\title{
Geodetic Constraints on the Qinghai-Tibetan Plateau Present-Day Geophysical Processes
}

\author{
Kamil Erkan ${ }^{1}$, C. K. Shum ${ }^{1, *}$, Lei Wang ${ }^{1}$, Junyi Guo ${ }^{1}$, Christopher Jekeli ${ }^{1}$, Hyongki Lee ${ }^{1}$, \\ Wendy R. Panero ${ }^{1}$, Jianbin Duan ${ }^{1}$, Zhenwei Huang ${ }^{1}$, and Hansheng Wang ${ }^{2}$ \\ ${ }^{1}$ School of Earth Sciences, The Ohio State University, Columbus, Ohio, USA \\ ${ }^{2}$ Key Laboratory of Dynamic Geodesy, Institute of Geodesy and Geophysics, Chinese Academy of Sciences, Wuhan, China
}

Received 10 May 2010, accepted 27 September 2010

\begin{abstract}
The Qinghai-Tibetan Plateau is the largest and the highest area in the world with distinct and competing surface and subsurface processes. The entire Plateau has been undergoing crustal deformation and accompanying isostatic uplift as a result of the Cenozoic collision of the Indian and Eurasian continents. Regional secular surface mass changes include the melting of mountain glaciers and ice caps, and permafrost layer degradation due to global warming. There is also a plausible effect of glacial isostatic adjustment due to the removal of a possible Pleistocene ice-sheet. In this article, we present an assessment of the sizes and extents of these competing interior and exterior dynamical processes, and their possible detections using contemporary space geodetic techniques. These techniques include, in addition to GPS, satellite radar altimetry over land, and temporal gravity field measurements from the Gravity Recovery and Climate Experiment (GRACE) satellite mission. These techniques are complementary: land satellite altimetry, similar to GPS, is sensitive only to surface uplift, whereas GRACE is sensitive to both surface uplift and mass changes inside the Earth. Each process may dominate the others in a particular region. Our analysis shows that GRACE data are more sensitive (than GPS or land altimetry) to hydrologic and meteorology signals, some of which are larger than the combined effect of geodynamic processes and permafrost degradation.
\end{abstract}

Key words: Tibetan plateau, Isostatic uplift, Permafrost, Satellite altimetry, GRACE

Citation: Erkan, K., C. K. Shum, L. Wang, J. Guo, C. Jekeli, H. Lee, W. R. Panero, J. Duan, Z. Huang, and H. Wang, 2011: Geodetic constraints on the Qinghai-Tibetan Plateau present-day geophysical processes. Terr. Atmos. Ocean. Sci., 22, 241-253, doi: 10.3319/TAO.2010.09.27.01(TibXS)

\section{INTRODUCTION}

The Qinghai-Tibetan Plateau is a unique geophysical region of the world with its extreme size and elevation. Despite its location at low latitudes, the Tibetan Plateau presently contains the largest storage of ice after Antarctica, Greenland, and the Arctic, and it has rightfully being called the "Third Pole" (Qiu 2008) and the "World Water Tower" (Xu et al. 2008). Several competing geodynamic processes are active on the plateau which motivates studies using contemporary geodetic sensors in the region. First, the plateau forms the back arc of the active Eurasian-Indian tectonic collision zone, and the entire plateau has been tectonically active (Molnar et al. 1993; Tapponnier et al. 2001). The horizontal deformation on the plateau has been investigated

\footnotetext{
* Corresponding author

E-mail: ckshum@osu.edu
}

intensively and quantified by dense GPS networks (Wang et al. 2001). These rates show general agreements with relative motions of the major fault and suture zones in the plateau (Meade 2007). Figure 1 shows contemporary GPS horizontal velocities with error eclipses in the Himalayan-Tibetan continental collision zone [figure courtesy, Q. Wang, updated from Wang et al. (2001)].

Many geologic and geophysical studies indicate that the present-day Tibetan Plateau has formed during $>40 \mathrm{My}$ of the continental collision (Tapponnier et al. 2001; Rowley and Currie 2006). Determination of present-day tectonic uplift rates has been limited and challenging using modern geodetic sensors such as GPS and gravimetry. For example, Sun et al. (2009) estimated uplift rates and crustal thickening rates at three locations in Tibet, by combined measurements from absolute gravimetry and three continuous GPS stations. 


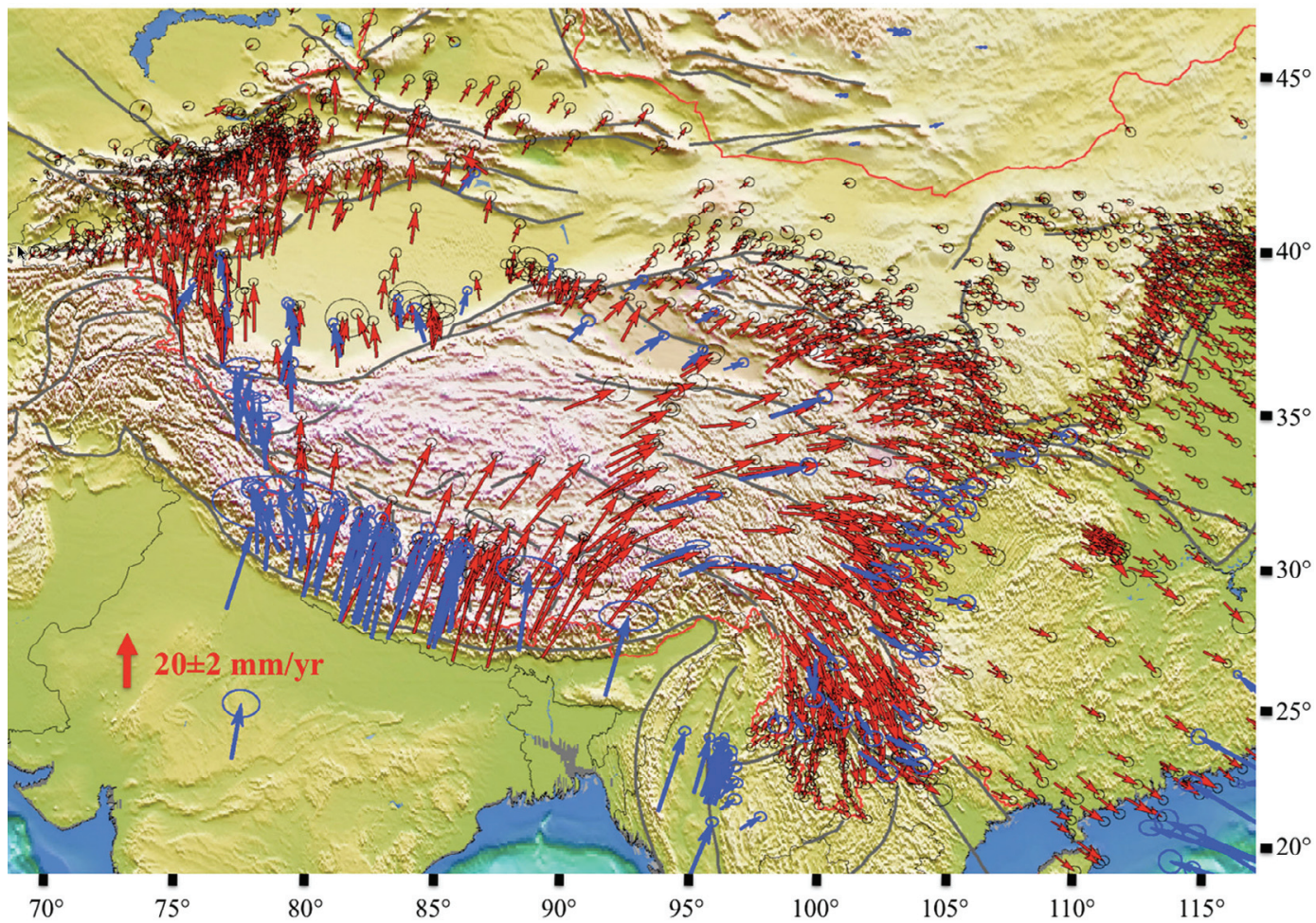

Fig. 1. The Himalayan-Tibetan continental collision zone with contemporary GPS horizontal velocities with error eclipses [figure courtesy, Q. Wang, updated from Wang et al. (2001)]. Grey lines show the approximate main structural boundaries. Red and blue arrows indicate previous and new GPS solutions, respectively.

Present-day vertical motion includes the response of the Earth crust to the retreat of mountain glaciers and permafrost layer degradation over the plateau as a result of anthropogenic climate change. During the past half-century, $82 \%$ of the plateau's glaciers have retreated, and $10 \%$ of the thickness of the discontinuous and sporadic permafrost has degraded (Qiu 2008). In the presence of a warmer climate, the Tibetan Plateau will likely experience increased atmospheric water vapor content and precipitation (Xu et al. 2008), despite the rapid depletion of glaciers and degradation of permafrost. The latter creates a significant problem for sustained habitability because of the gradual depletion of regional water resources.

To make the problem even more complicated, because of the extreme elevations over a large area, it has been proposed that the present Tibetan Plateau may be experiencing the glacial isostatic adjustment (GIA) process, similar to what is observed over Fennoscandia and present-day Hudson Bay region in North America. The size and extent of the hypothesized Pleistocene ice-sheet is still being debated (Derbyshire et al. 1991). Various glaciation scenarios have been recently discussed in the literature and their expected GIA signals have been modeled (Wang 2001; Kaufmann 2005).

Vertical geodetic rate measurements over the plateau are limited. A continental scale repeated leveling survey over China revealed positive uplift rates $\left(2-4 \mathrm{~mm} \mathrm{yr}^{-1}\right)$ in the western Tibet and slightly negative rates $\left(0\right.$ to $\left.-2 \mathrm{~mm} \mathrm{yr}^{-1}\right)$ in the eastern parts of Tibet (Zhang et al. 1989). However, the leveling results are largely in contradiction with the limited number of vertical GPS measurements have been reported so far. Xu et al. (2000) conducted three campaigns between 1993 and 1997 and reported vertical rates at 14 locations in central Tibet. Excluding one outlier and four stations in southern Tibet, their estimated uplift rates are between 1.1 - $9.8 \mathrm{~mm} \mathrm{yr}^{-1}$. Recently, Yao (2008) published a map of vertical rates based on sparse data of repeated GPS measurements; the data show slightly positive rates $(0$ $10 \mathrm{~mm} \mathrm{yr}^{-1}$ ) over the entire Tibetan Plateau. In general, the reported vertical GPS rates show large spatial variations and the solution differences are either comparable or higher than the calculated rates, indicating significant unreliability. In addition, most of the GPS velocities over the plateau have been obtained via campaigns, thus the GPS time series cannot resolve seasonal or shorter signals. About half of the existing GPS sites are on or were on bedrock when measurements were taken, the remaining sites are on soil or on permafrost (Qi Wang, personal communication, 2009). For example, the continuous GPS site at Lhasa is on the roof of a building and not directly built on bedrock. All of these problems contribute to GPS rates, particularly for vertical uplift estimates. 
Figure 2 is a schematic which summarizes the active competing geophysical and climatic processes taking place over the Tibetan Plateau, along with plausible contemporary space geodetic techniques, which could provide constraints and thus potentially separate some of these processes. In this study, we present an assessment of the magnitudes of these processes and their possible detections or constraints using multiple satellite geodetic techniques in addition to GPS, namely radar altimetry from TOPEX/ POSEIDON measuring solid Earth deformation which has been demonstrated over the land region of Hudson Bay observing glacial isostatic adjustment (Lee et al. 2008a), and space gravimetry from the Gravity Recovery and Climate Experiment (GRACE) twin-satellites (Tapley et al. 2004). The former is sensitive only to surface changes, whereas the latter is sensitive to both surface and subsurface changes. Therefore, it is possible for these two techniques to be used in a complementary manner to discern a certain geophysical mechanism. In particular, quantification of the vertical elastic deformation along the major faults, and the extent of regional permafrost degradation rates are two of the important contemporary scientific problems.

\section{PRESENT TECTONIC ACTIVITY}

\subsection{Isostatic Tectonic Uplift}

The Tibetan Plateau constitutes the back arc region of the active Himalayan orogen that started with the collision of the Eurasian and Indian continents 40 - $50 \mathrm{Ma}$ (Molnar et al. 1993). During the period of collision, the area that defines the present Tibetan Plateau experienced more than $2000 \mathrm{~km}$ north-south shortening, gained more than $4 \mathrm{~km}$ in elevation, and underwent a crustal thickening of more than twice typical continental values. The elevation history of the plateau has been studied for decades to understand the dynamics of the continental collision. It has also been suggested that the increased elevation of Tibet is directly responsible for a strengthening of the Indian monsoon (Molnar et al. 1993).

The general mechanism governing the high elevation of the Tibetan Plateau can be explained by the Airy type isostatic compensation (Braitenberg et al. 2000), in which the surface of the Earth responds to thickening of the crust by uplift. This simple isostatic mechanism was shown to be valid for the majority of the plateau except near the margins (Jin et al. 1994; Braitenberg et al. 2000). On the other hand, Jimenez-Munt et al. (2008) argued that the gradual decrease of the crustal thickness toward the north despite the constant elevation implies that isostacy is maintained below the crust in the northern Tibet (discussed below).

Many independent observations suggest that the Tibetan Plateau started to rise in the south where it meets the Himalayas and has been extruding towards the interior of Eurasia over the course of continental collision (England and Houseman 1986). Studies based on the historic faulting

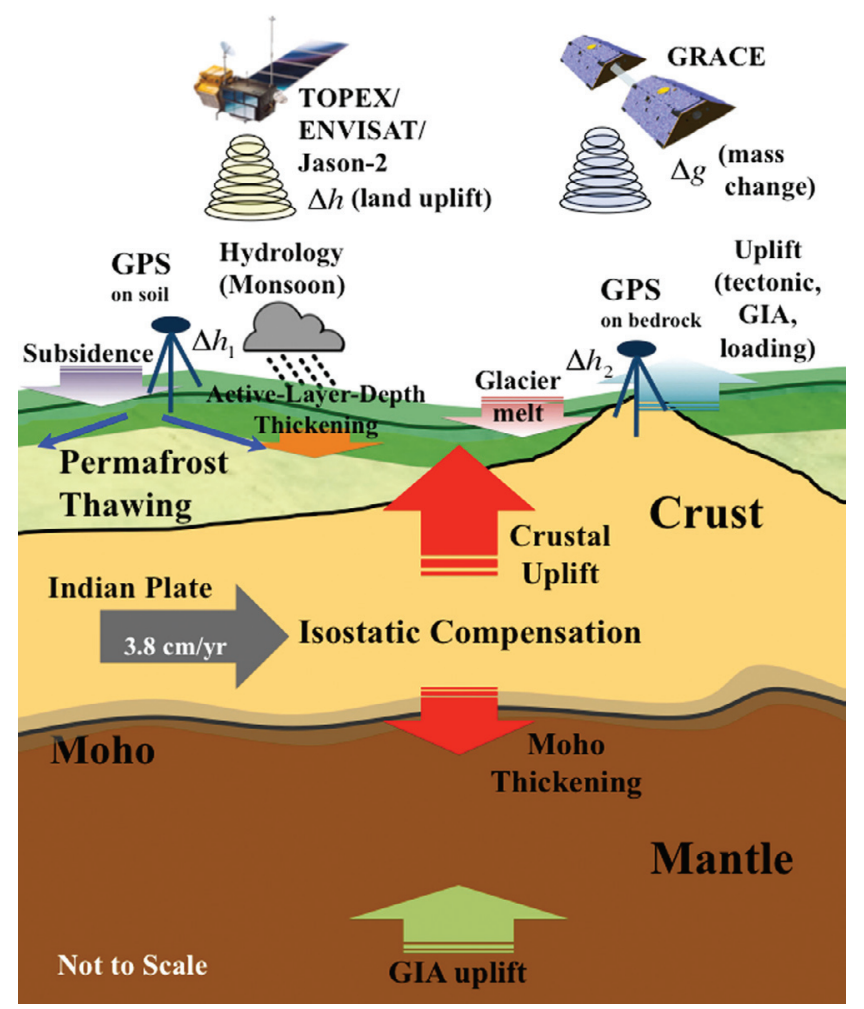

Fig. 2. A schematic representation of the surface and subsurface geophysical processes in the Tibetan Plateau and the various satellite geodetic techniques proposed to constrain these processes. Distances are not to scale.

in the region (Tapponnier et al. 2001) suggest a decreasing age of the thrust faulting toward the north. Combined results of paleo-altimetry measurements based on oxygen isotope variations trapped in lake sediments show younger elevations toward the north (Mulch and Chamberlain 2006; Rowley and Currie 2006). The crustal extrusion model has been already demonstrated by theoretical (Bird 1991), numerical (England and Houseman 1986; Beaumont et al. 2004), and laboratory (Royden et al. 1997) models.

Seismic (Li et al. 2006; Xiong et al. 2009) and regional gravity (Jin et al. 1994; Shin et al. 2009) studies show that the Moho is deepest in the central part of the plateau and gradually becomes shallower toward the margins of the plateau. A comparison of the Moho depths and plateau age for some localities in Tibet is shown in Fig. 3. Based on the empirical relationship shown in Fig. 3 (dashed lines), we estimated a crustal thickening model and corresponding present-day isostatic uplift rates (assuming Airy type isostacy). A more detailed discussion of this model with its justifications is intended for an independent study.

The model estimated present-day isostatic uplift rates are shown in Fig. 4. According to this, the north-east and south-west parts of the plateau experience the maximum amounts of present-day uplift, whereas the central plateau experience little to no tectonic uplift; these are in general 
agreement with the results of other studies (e.g., Rowley and Currie 2006). Note that the estimated uplift rates include isostatic conditions only; therefore, regions with nonisostatic conditions were masked in Fig. 4. We used the free-air gravity field of EGM2008 (Pavlis et al. 2008) and removed areas with gravity anomalies larger than a certain amount. As expected, areas away from the margins of the plateau are isostatically compensated, with the exception of Qaidam basin.

\subsection{Interseismic Elastic Deformation}

According to the elastic rebound theory, stress accumulation during an interseismic period accompanies both horizontal and vertical deformations. These effects are largest near the fault zones and dissipate quickly away from the faults. In the Himalayan-Tibetan orogen these effects dominate all others on the Himalayan arc. Leveling measurements across the Himalayas reveal vertical rates of more than $10 \mathrm{~mm} \mathrm{yr}^{-1}$ (Zhang et al. 1989; Jackson and Bilham 1994). Over the Tibetan plateau, vertical motions due to interseismic deformation are expected to be much smaller except near the margins. In the eastern margin of the high plateau, repeated leveling surveys with respect to the Sichuan basin show vertical rates of $2-5 \mathrm{~mm} \mathrm{yr}^{-1}$ (Wang et al. 2008). However, it is not clear that these rates represent purely elastic loading, since other effects such as non-isostatic uplift and rapid exhumation may also occur near the margins.
In the interior of the plateau, far from the margins, the majority of deformation is by strike-slip motion which is expected to have smaller vertical components. However, as Meade (2007) showed these strike-slip faults also have significant normal and reverse components. Therefore, the situation may be more complicated than a simple strike-slip activity. Meade (2007) also showed that the majority of the

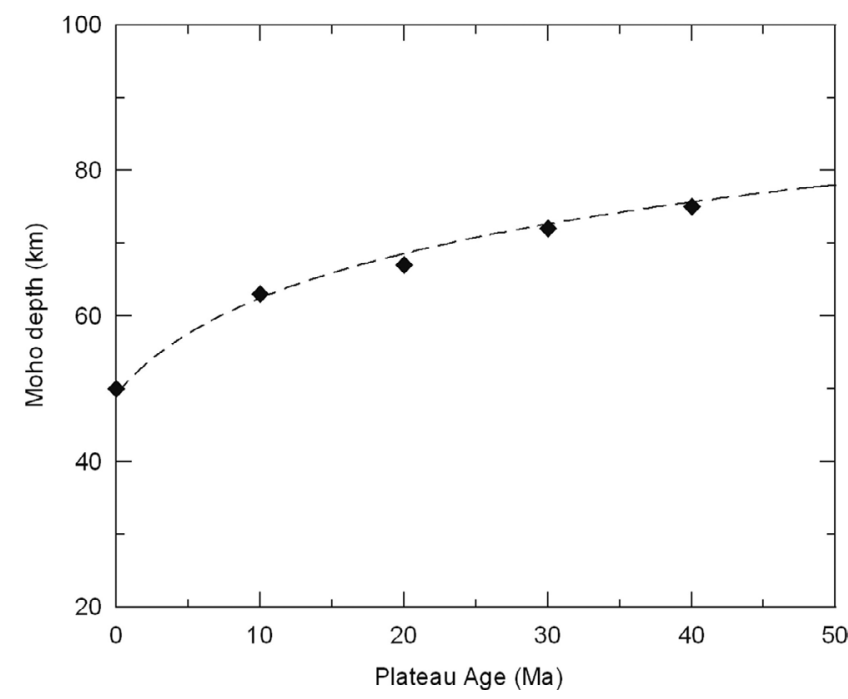

Fig. 3. A plot showing the empirical relation between plateau age and Moho depths in Tibet. The dashed line shows a plausible fit for the data. See the text for details.

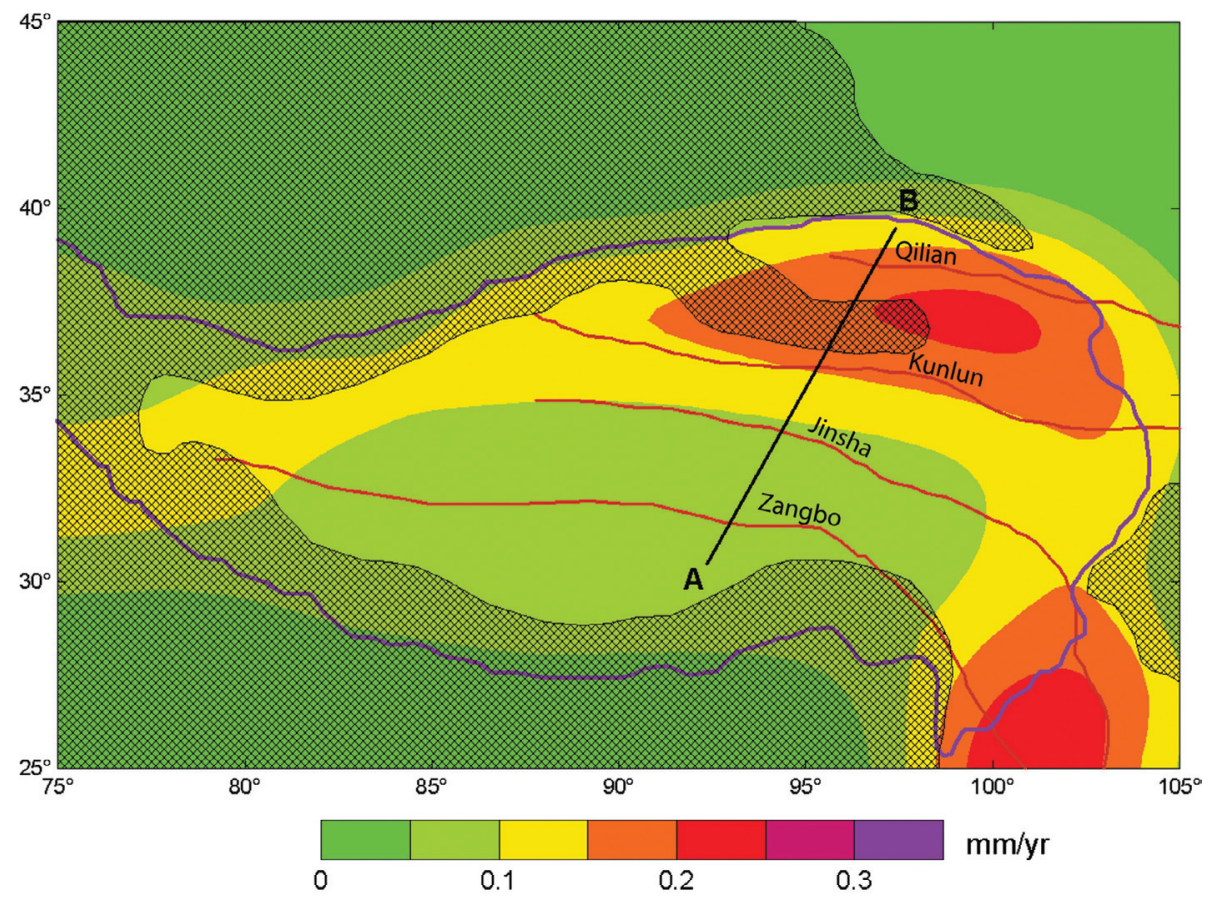

Fig. 4. Model estimated present-day isostatic uplift rates in the Tibetan Plateau. The crosshatched areas show the isostatically uncompensated areas where the model is not applicable. Dark red lines show the suture zones separating major structural blocks (Tapponnier et al. 2001). Profile A - B is shown for Fig. 5. 
current horizontal GPS rates can be explained by motions along several major fault zones in the interior of the plateau (Fig. 4, blue lines). Using this assumption, we conduct a simple quantitative analysis of vertical interseismic rates along a north-south profile (see Fig. 4 for profile location). We use the slip rates given in Meade (2007), and assume constant rates during an interseismic period of 200 years for all faults. The rates are calculated using the dislocation code of Wang et al. (2006). Figure 5 shows the calculated vertical rates along the profile. We find significant rates (1 $\left.2 \mathrm{~mm} \mathrm{yr}^{-1}\right)$ in the vicinity of the fault zones $( \pm 10 \mathrm{~km})$; and also observe that these rates diminish quickly away from the fault zones.

\section{SURFACE PROCESSES}

\subsection{Permafrost Degradation}

The permafrost region of the Tibetan Plateau covers the largest area in low-mid latitudes of the world (Wang and French 1995; Zhao et al. 2000; Zhang et al. 2008). Currently, $\sim 75 \%$ of the plateau is overlain by a permafrost layer (Fig. 6a). The layer is either discontinuous (50 - 90\% coverage; mainly the northern half of the permafrost region) or sporadic (10 - 50\% coverage; mainly the southern half of the region) in nature (Zhang et al. 2008). The permafrost layer starts $\sim 1-15 \mathrm{~m}$ below the ground where annual temperature variations are diminished, and extend down to $\sim 150 \mathrm{~m}$ where the geothermal conditions exceed the melting point of ice.

The permafrost in Tibet is characterized to be "warm" because of the high geothermal gradients in the Tibetan Plateau (An and Shi 2007). This makes the layer more susceptible to climatic changes compared to permafrost zones over the high latitudes (Wang and French 1995). Consider- ing that the present global warming rates in Tibet, primarily because of its altitude, are three times faster than the global average (Qiu 2008), the top of the permafrost layer has undergone rapid degradation. Over the last 15 years, $10 \%$ of the total permafrost ice mass has disappeared (Wang et al. 2000). Continuing with these degradation rates, the entire permafrost layer is projected to vanish in the next 150 years (Wang and French 1995).

Effects of permafrost degradation include both subsurface mass removal and the elastic rebound of the Earth in response to mass removal. Considering the widespread effect of mass removal, the permafrost degradation signals presumably have a profound effect on the regional vertical rates. Oelke and Zhang (2007) generated a regional thermal model using available climatic data, and calculated ActiveLayer Depth (ALD, or the depth of the layer which freezes

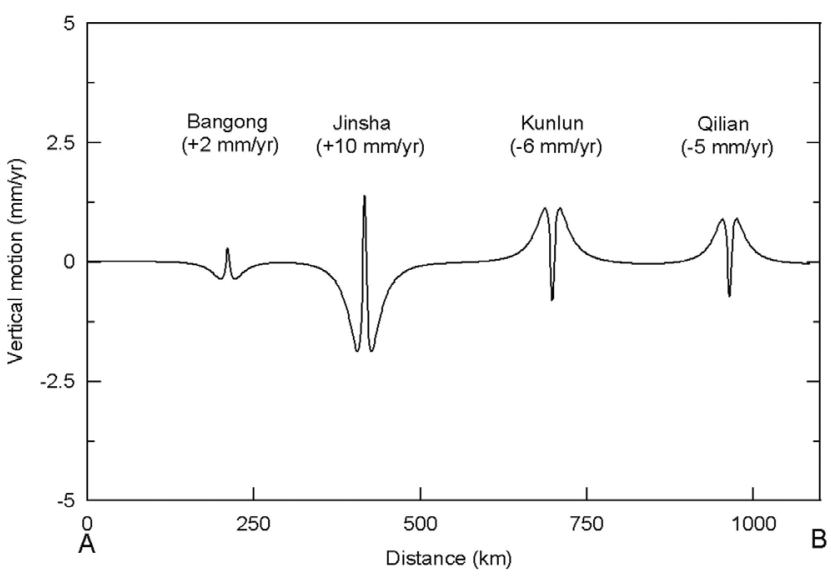

Fig. 5. Calculated interseismic vertical deformation rates along Profile A - B in Fig. 4. In parentheses, negative rates show compression and positive rates show extension (Meade 2007). See the text for details. (a)

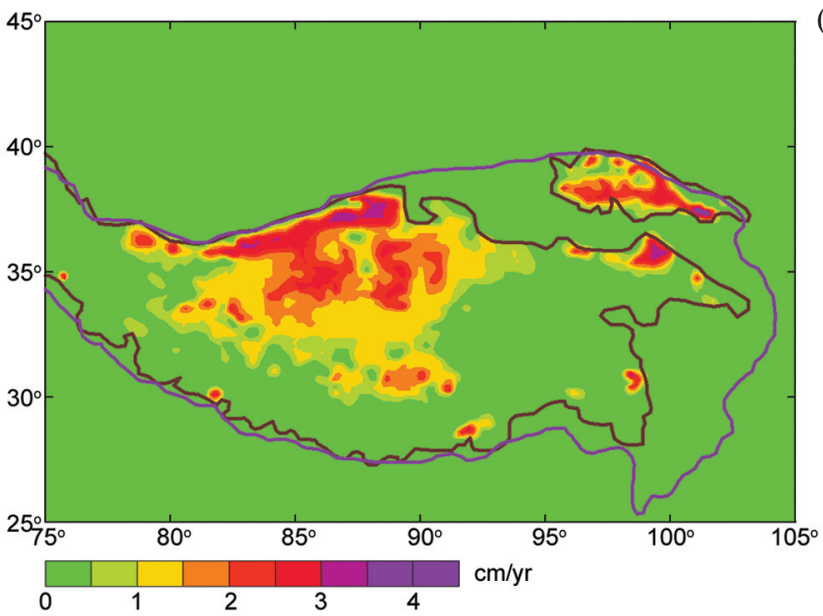

(b)

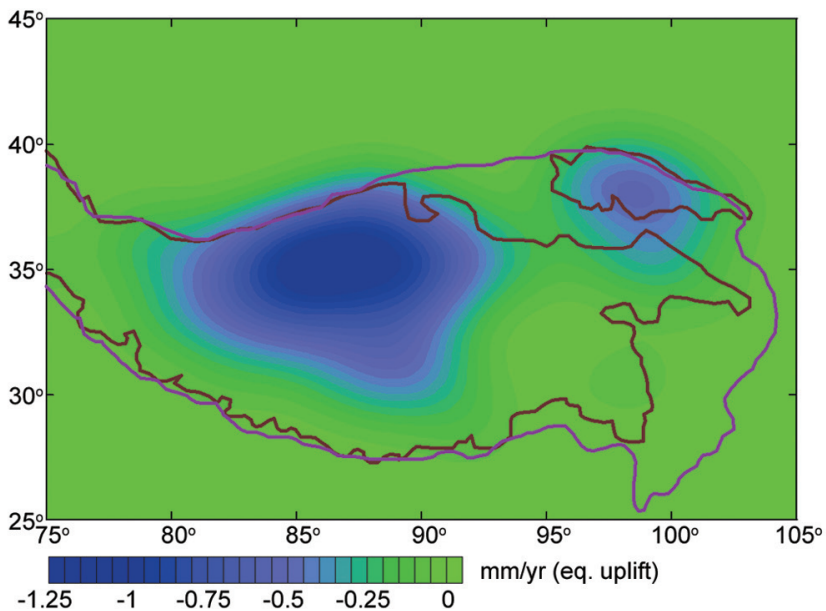

Fig. 6. (a) Estimated ALD deepening rates [modified from (Oelke and Zhang 2007)]. The boundary of the permafrost region is shown by heavy dark brown lines. (b) The net rate of permafrost ice removal rates (see the text). A $200 \mathrm{~km}$ Gaussian filter is applied, and rates are converted into equivalent rock uplift. 
and thaws every year) thickening rates over the Tibetan Plateau. Their model reveals that the ALD thickening rates are $\sim 14 \mathrm{~mm} \mathrm{yr}^{-1}$ in the majority of the permafrost region, 1980 - 2001, and the rates are as high as $40 \mathrm{~mm} \mathrm{yr}^{-1}$ in some locations [Fig. 6a, modified from Oelke and Zhang (2007)]. It should be noted that the ALD thickening rate is not directly comparable with GPS, or land altimetry measured uplift rates.

\subsection{Asia High-Mountain Glaciers}

While the largest recent contributions of the glaciers to sea-level rise include the Patagonia and the Alaskan glaciers (Cogley 2009), the so-called Asian High Mountain glaciers are the least observed and have the largest uncertainty in their mass balance estimates. The Asian High Mountain glaciers are comprised of eight mountain glacier systems, Himalayan (glacier area $\sim 33050 \mathrm{~km}^{2}$ ), Tien Shan (15417 $\mathrm{km}^{2}$ ), Pamirs $\left(12260 \mathrm{~km}^{2}\right)$, Kun Lun $\left(12260 \mathrm{~km}^{2}\right)$, Quilan Shan $\left(1930 \mathrm{~km}^{2}\right)$, Tibet $\left(1802 \mathrm{~km}^{2}\right)$, Gongga $\left(1580 \mathrm{~km}^{2}\right)$, and Dzhungaria $\left(1000 \mathrm{~km}^{2}\right)$, representing a total glacierized area of $79299 \mathrm{~km}^{2}$ with the Himalayan glaciers being the largest (Dyurgerov and Meier 2005). The Himalayas alone encompasses $\sim 15000$ glaciers, which stores $12000 \mathrm{~km}^{3}$ of freshwater. Matsuo and Heki (2010) used GRACE data and estimated a significantly larger Asian High Mountain glacier mass balance than the in situ estimates (Kaser et al. 2006; Cogley 2009), however, pointing out the geodynamic processes, GIA and tectonics, need to be accounted for to accurately estimate the glacier mass balance in the region. Conversely, the glacier mass balance must be known to quantify geodynamic signals in this region. In addition, removal of glacier mass or its ablation also causes elastic loading of the crust, which needs to be accounted for to study tectonics in the region.

\subsection{Pleistocene Deglaciation}

Holocene global warming caused removal of broad ice sheets on the surface of the Earth. Such a glaciation possibly reached its maximum at 20 Ky B.P., and started to diminish until 10 Ky B.P. (Wang 2001). Unloading of the ice sheets resulted in glacial isostatic adjustment of the lithosphere that presently continues due to the finite viscosity of the asthenosphere. The main effects of GIA include surface uplift and the subsurface uplift at the Moho, due primarily to the viscoelastic rebound of the mantle resulting from deglaciation or removal of large ice-sheets located on the crust.

The extent of Pleistocene glaciation in Tibet has been under discussion because of uncertainties with regard to the causes and interpretation of present-day uplift. Derbyshire et al. (1991) proposed that only $15 \%$ of the plateau (located in the trans-Himalaya region) was covered by glaciers, whereas Kuhle (1988) suggested a much larger ice-sheet of
$1 \mathrm{~km}$ thick covering the entire plateau. If the former is true then the effect of GIA on present-day uplift rates is negligible. For the latter, surface uplift rates of $1-2 \mathrm{~mm} \mathrm{yr}^{-1}$ are expected for the majority of the plateau (Wang 2001; Kaufmann 2005). Figure 7 shows current GIA models for the Tibetan Plateau. Figure 7 (upper left panel) shows the predicted GIA uplift using the KUHLE ice model (Kuhle 1998), and KL1 Earth model (Kaufmann 2005). Figure 7 (upper right panel) shows the predicted GIA uplift for ice model TIBET4, with Earth model KL1 (Kaufmann 2005). Figure 7 (lower left panel) shows the predicted GIA uplift for ice model TIBET6, with Earth model KL1 (Kaufmann 2005). Finally, Fig. 7 (lower right panel) shows the predicted GIA uplift using the KUHLE ice model with a viscosity model C (Table 1 in Wang et al. 2001). As discussed before, the presence of a large Pleistocene ice-sheet over the Tibetan Plateau is largely controversial, and the current models reflect drastically different predicted uplift due to GIA, if there is such a significant geodynamical process.

\section{SATELLITE GEODETIC TECHNIQUES}

Over the Tibetan Plateau, there have been very few ground measurements of accurate vertical rates to constrain and separate the above mentioned geodynamical and climatic processes. Observations of geodetic quality include a few vertical rates obtained by GPS (Xu et al. 2008; Yao 2008), and the long-term leveling surveys (Zhang et al. 1989; Wang et al. 2008). One of the permanent GPS stations is located in Lhasa where Matsuo and Heki (2010) reported $\sim 3 \mathrm{~mm} \mathrm{yr}^{-1}$ after epoch 2000.5. This value is in good agreement with results by Xu et al. (2008). Sun et al. (2009) performed combined absolute gravimetry at three GPS stations in various parts of Tibet. All GPS measurements showed uplift in the three areas and gravity changes are negative. Sun et al. (2009) attributed these observations to the ongoing crustal thickening in Tibet. We note that instruments like GPS or leveling are sensitive to surface uplifts, but cannot detect Moho deepening, nor discriminate between processes acting on the surface uplift, such as permafrost degradation and crustal thickening.

The Gravity Recovery and Climate Experiment (GRACE) spaceborne gravimetry has demonstrated that it can measure gravity changes induced by mass transport in the Earth's system with a temporal resolution of weeks and a spatial resolution as fine as $400 \mathrm{~km}$. (Tapley et al. 2004). The tectonic processes discussed above are occurring over very large spatial scales (in excess of $1000 \mathrm{~km}$ ). The GRACE signals need to be further processed including smoothing or filtering, and de-correlation or destriping or to reduce the geographically-correlated high frequency errors (Swenson and Wahr 2002, 2006; Duan et al. 2009; Guo et al. 2010). Since GRACE measures the total mass change, it is sensitive to hydrology, surface uplift and changes in 
(a)

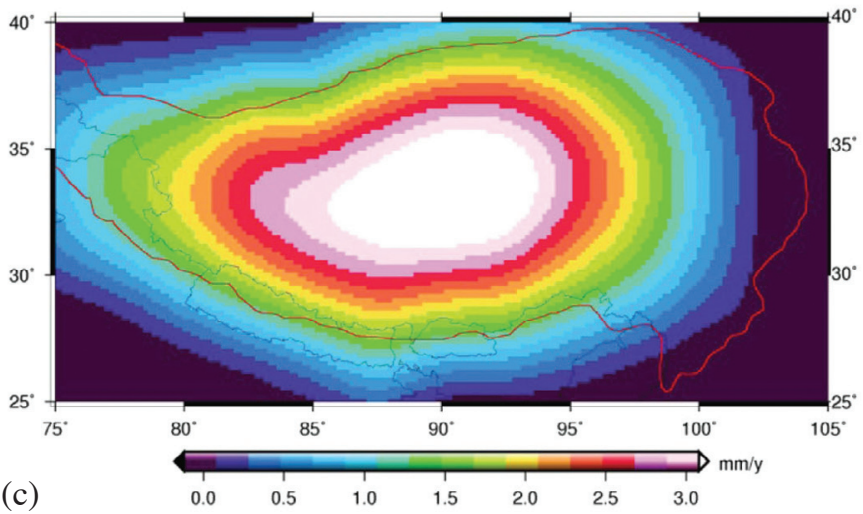

(c)

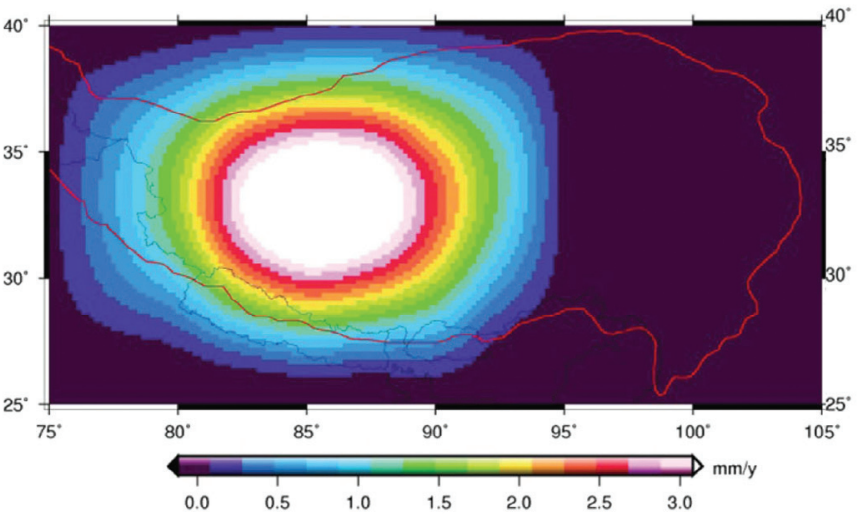

(b)

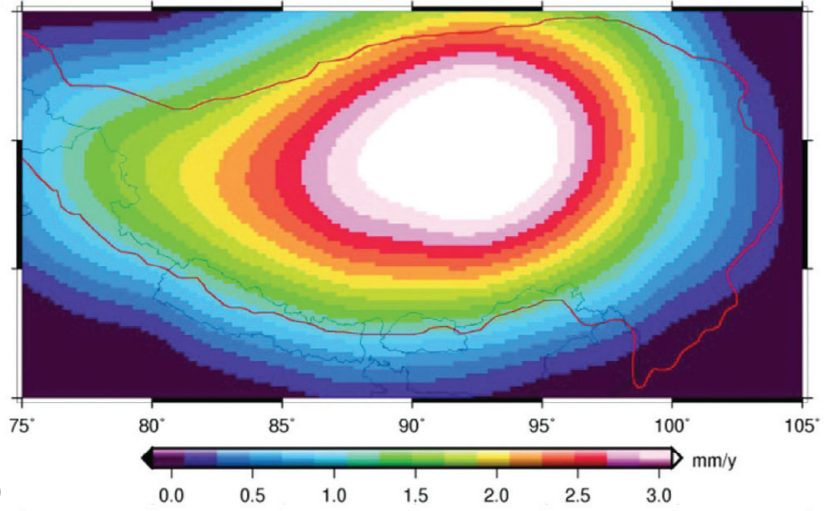

(d)

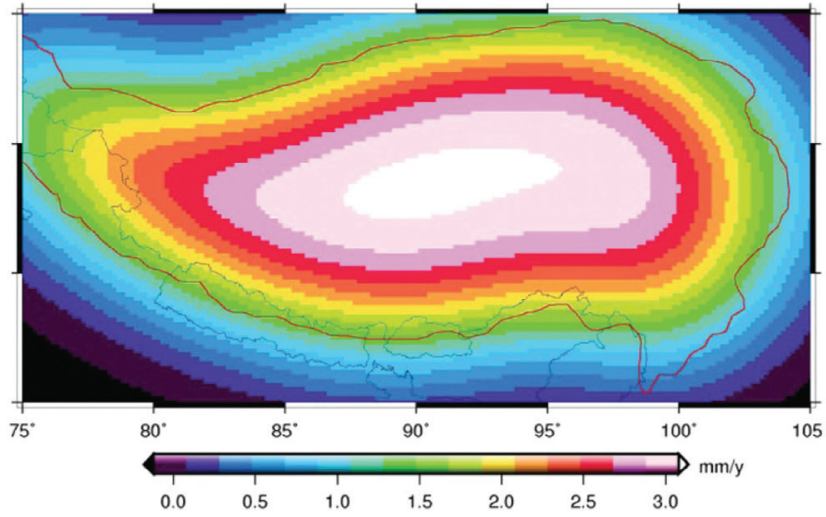

Fig. 7. Contemporary GIA models for the Tibetan Plateau. (a) Predicted uplift due to GIA using the KUHLE ice model and KL1 Earth model (Kaufmann 2005). (b) Predicted GIA uplift for the ice model TIBET4 and KL1 Earth model (Kaufmann 2005). (c) Predicted GIA uplift for the ice model TIBET6 and KL1 Earth model (Kaufmann 2005). (d) Predicted GIA uplift using the KUHLE ice model with a viscosity model C (Wang et al. 2001).

the Earth's interior, with sensitivity down to the core-mantle boundary.

The changes of the permafrost active layer can theoretically be measured by satellite gravity, if one could overcome the current coarse resolution of GRACE and be able to separate the signal from other competing signals, including hydrology, tectonics, and aliasing of hydrologic signals from outside of the Tibetan Plateau. Effective rates for GRACE are substantially lower than the calculated ALD deepening rates (Fig. 6b) because of the discontinuous or sporadic distribution of the permafrost and small ratio of ice $(10-20 \%)$ content in the permafrost zones (Zhang et al. 2008). In our calculations (Fig. 6b), we used a generic value of $60 \%$ for continuity of the permafrost coverage and $20 \%$ for the ice content of the permafrost layer. We note that removal of subsurface ice in the permafrost layer results in the elastic rebound of the crust, these rates are assumed to be negligibly small in our case, and therefore were not included in calculating the geodetic effect of permafrost degradation (Fig. 6b).

Here we show the observed mass change over the Tibetan Plateau region using GRACE (Tapley et al. 2004) data. We used the University of Texas Center for Space Re- search GRACE Release 04 (RL04) Level 2 monthly Stokes coefficient data products $\left(l_{\max }=60\right)$ over the Tibetan Plateau and its vicinity for the time span January 2003 - December 2009. We first remove a mean or averaged gravity field over a data span of 2003 through 2009. Then we post-processed the data using de-correlation, filtering and signal leakage correction techniques (Duan et al. 2009; Guo et al. 2010). Here we choose a Gaussian filter with radius of $300 \mathrm{~km}$. Then we compute the monthly Stokes Coefficients as geoid changes, and the GIA signal is removed using the Paulson GIA model (Paulson et al. 2007). We also applied geocenter $(l=1)$ correction using satellite laser ranging solutions ( $\mathrm{J}$. Ries, personal communication). The missing month, June 2003 , is compensated by interpolation using data from two adjacent months. The GRACE monthly mass variations are computed as follows (Wahr et al. 1998):

$$
\begin{aligned}
\Delta \sigma(\theta, \phi)= & \frac{R \rho_{a v e}}{3} \sum_{l=0}^{l_{\max }} \sum_{m=0}^{l} \widetilde{P}(\cos \theta) \frac{2 l+1}{1+k_{l}} \\
& \times\left[\Delta C_{l m} \cos (m \phi)+\Delta S_{l m} \sin (m \phi)\right]
\end{aligned}
$$

where $k_{l}$ are load Love numbers, and $\Delta C_{l m} \& \Delta S_{l m}$ are 
Stokes coefficients change of degree $l$ and order $m$. We did not remove hydrologic signals using GLDAS or VIC models, primarily because the models are not accurate enough to predict the true hydrologic signals (results not shown here). Then a trend is computed simultaneously estimating semiannual and annual signals over the Tibetan Plateau and its vicinity. Figure 8 shows the GRACE observed trend (in terms of water thickness change, $\mathrm{mm} \mathrm{yr}^{-1}$ ). The white areas are glacier locations from Global Land and Ice Measurements from Space (GLIMS) database (Ohmura 2009). Two example locations in Fig. 8 show the uplifts (and their formal uncertainties) estimated using TOPEX (1992 - 2002) land altimetry data over the Qaidam Basin, and in the central Tibetan Plateau. Note that GRACE and TOPEX are computed in terms of different quantities, water thickness change and uplift, respectively, and thus their comparison is only qualitative.

A number of the signal shown in Fig. 8 can be explained. The large negative anomalies (deep blue) in northern India and south of Himalayan glaciers are reported to be mass losses due to groundwater depletion by human activities (Rodell et al. 2009; Tiwari et al. 2009). Mass loss over most of the glacier regions are due to glacier retreat (Matsuo and Heki 2010). The mass gain (red) in the regions of Qinghai Lake, south of Chengdu and southeast corner of Fig. 8 are most likely caused by interannual variations of Monsoon, precipitation and hydrologic variations (Lee et al. 2010). Possible changes in GIA are difficult to detect conclusively at this resolution. It is unclear whether the permafrost degradation signals are detectable since there is little resemblance in spatial variations between the GRACE signal and the permafrost ALD change by (Oelke and Zhang 2007). Improved GRACE data processing to enhance spatial resolution are needed for GRACE data to be effective in constraining or separating the competing geophysical processes over the Tibetan Plateau.

Satellite radar altimetry measurements, originally designed to observe deep-ocean sea level and circulation, have been used to detect solid Earth deformation, e.g., the Laurentian GIA, with an accuracy of several $\mathrm{mm} \mathrm{yr}^{-1}$ (Lee et al. 2008a, 2008b). The limitation of this technique is that the radar echo loses lock if the terrain is mountainous. Hence, it is challenging to achieve accurate vertical motion estimates from altimeter data over the parts of the Tibetan Plateau with rugged topography. Figure 9, showing the ellipsoidal heights over the Tibetan Plateau reveals the capability of TOPEX to sporadically maintain lock over these rough topographic surfaces. When data are available, it is difficult to estimate a reasonable vertical motion from a generated height change time series primarily because of errors caused by steep topography gradients. The height difference from cycle to cycle can reach several hundreds of meters, as can be seen from Fig. 10, and the gradient correction using Shuttle Radar Topography Mission (SRTM) C-band Digital

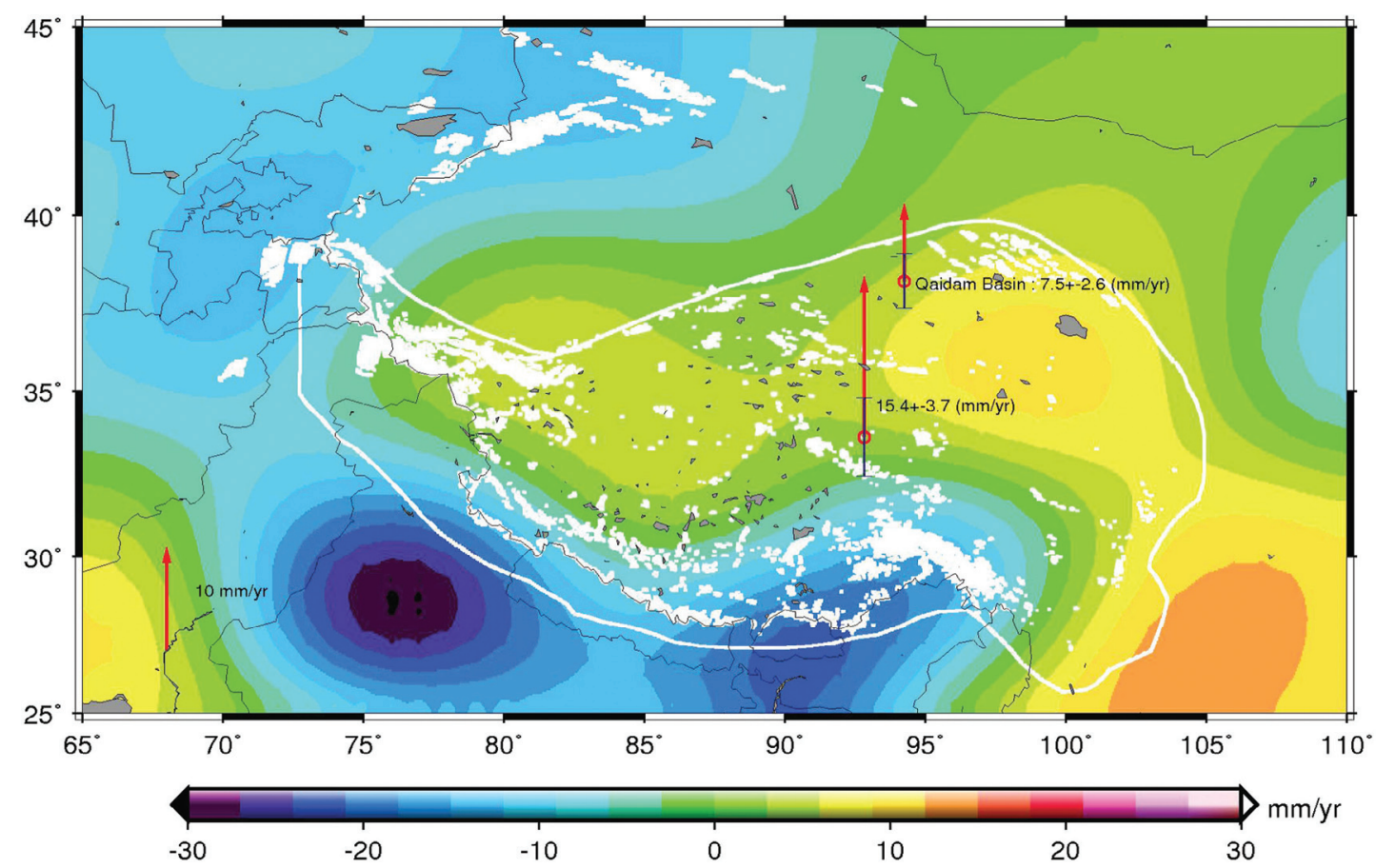

Fig. 8. GRACE secular trend (in terms of water thickness change, $\mathrm{mm} \mathrm{yr}^{-1}$ ) between 2002 and 2009 using the University of Texas Center for Space Research RL04 data product. Two example locations show the uplifts (and their formal uncertainties) estimated using TOPEX (1992 - 2002) land altimetry data over the Qaidam Basin, and central Tibetan Plateau. Note that GRACE and TOPEX are computed in terms of different quantities, water thickness change and uplift, respectively, and thus their comparison is only qualitative. 


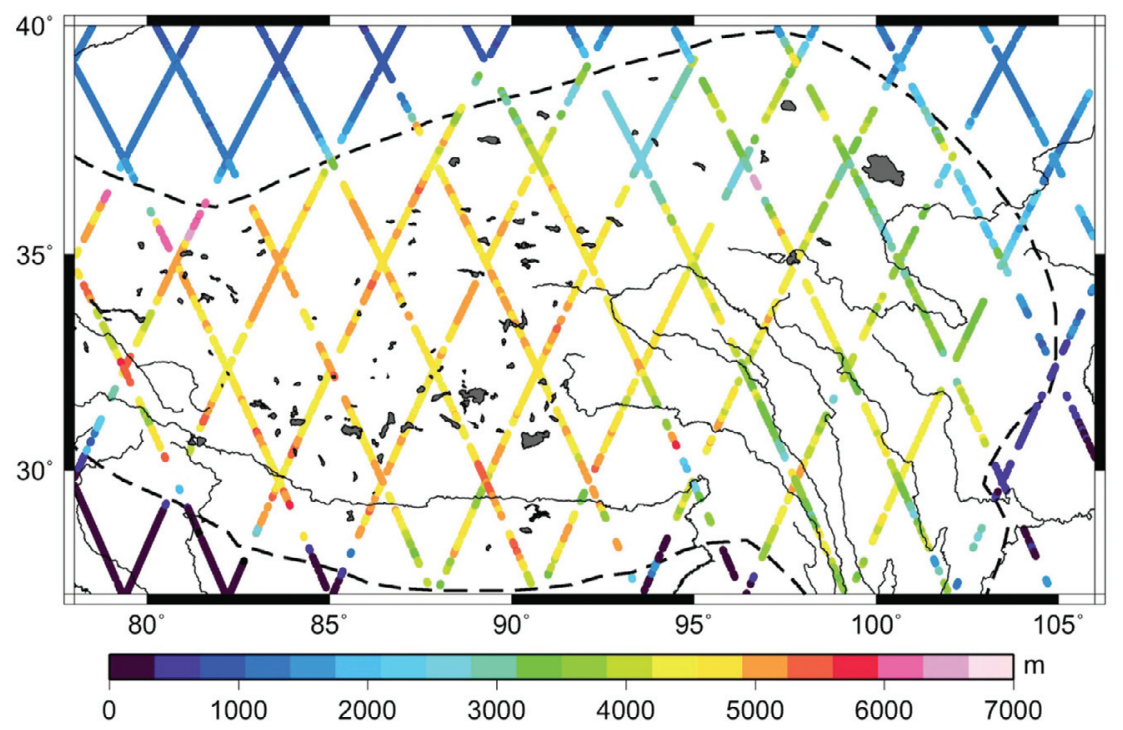

Fig. 9. TOPEX ellipsoidal heights from cycle 272 over the Tibetan Plateau. The dashed line shows the approximate boundary of the Plateau.

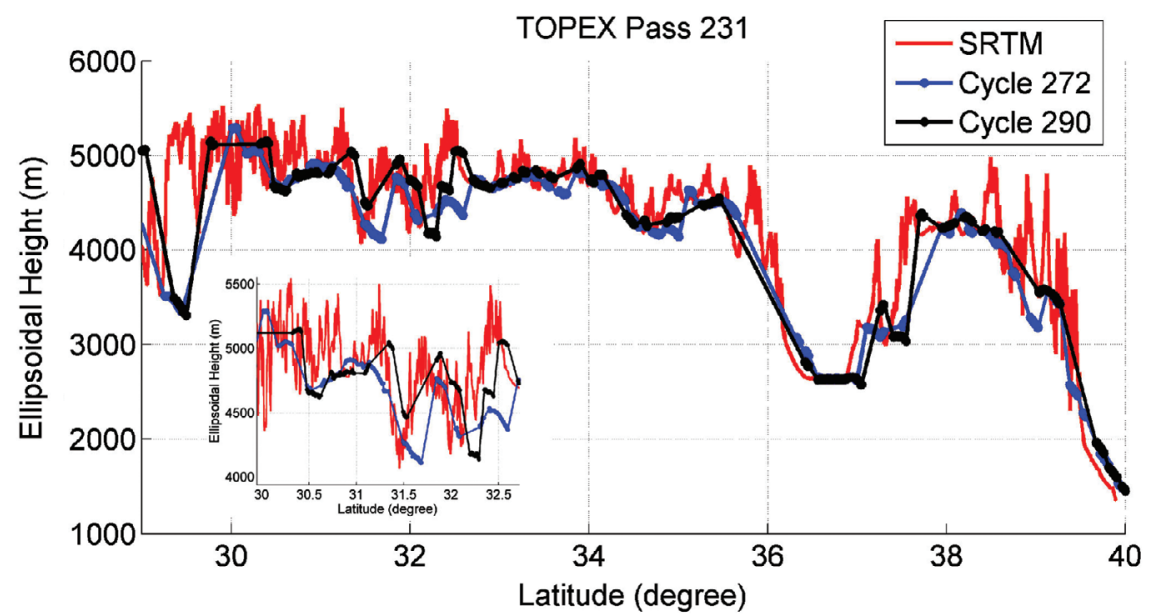

Fig. 10. TOPEX pass 231 profiles from cycle 272 and 290 over the Tibetan Plateau. The SRTM heights are converted to be referenced to the TOPEX ellipsoid. The zoomed figure is inserted for visual clarity.

Elevation Model (DEM) as in Lee et al. (2008b) could not mitigate the problem. We found that the currently available DEMs, including SRTM and GTOPO DEMs, are not adequate to correct the surface gradient changes for radar altimetry due to the DEM's errors, spikiness, and voids over the extreme terrains in the Qinghai-Tibetan Plateau. Instead, we used TOPEX 10-day repeat surface elevation measurements to generate mean profiles over relatively smooth study regions, which are used to mitigate the surface gradient errors in the time series of surface height changes. Here we show that it is possible to estimate vertical motion from TOPEX over the relatively smooth Qaidam Basin region, which is located at the northeastern Qinghai-Tibetan Plateau and in the central region of the plateau (Fig. 8). Two example time series are shown here (Fig. 11). We observed an uplift of
$7.5 \pm 2.6 \mathrm{~mm} \mathrm{yr}^{-1}$ in the Qaidam Basin, and an uplift of 15.4 $\pm 3.7 \mathrm{~mm} \mathrm{yr}^{-1}$ in the central Tibetan Plateau (Fig. 11, top and bottom, respectively), in qualitative agreement with the GRACE estimated trend in terms of water thickness change (Fig. 8). At present, land altimetry uplift observations are limited by the steep and rough terrain over the Tibetan Plateau causing the radar altimetry to be unreliable. Even if data are available, accurate and fine-resolution digital elevation models are not available to remove the gradient errors to align repeat-track radar altimeter measurements to form a height time series.

\section{CONCLUSIONS}

In this study, we estimated the magnitudes of regional 

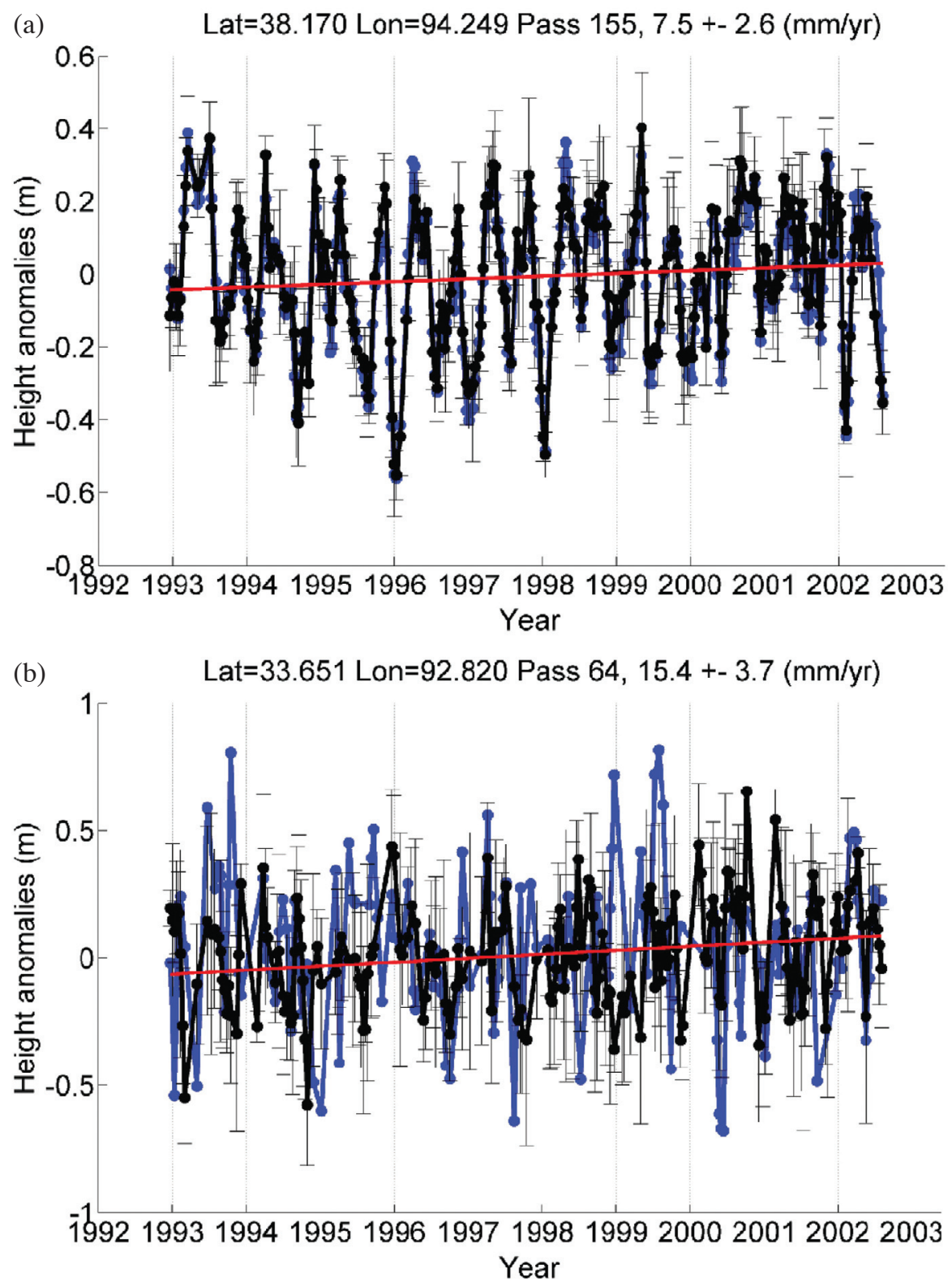

Fig. 11. (a) TOPEX land altimetry (pass 155) time series, 1992 - 2002, at a location over the western Qaidam basin, before (blue lines) and after (black lines) the gradient correction using a DEM generated using TOPEX surface elevation. The estimated vertical rate (with formal uncertainty) shows uplift. (b) TOPEX land altimetry time series (pass 64) and the estimated uplift (and its formal uncertainty) over a location in central Tibetan Plateau, before and after the gradient correction. Both uplift points are also shown in Fig. 8 for a qualitative comparison.

surface and subsurface processes over the Tibetan Plateau based on the available data in the region. We also calculated the effect of these processes using satellite geodetic methods, in particular, satellite radar altimetry and satellite gravimetry from GRACE. Multiple geodetic observations of varying spatial resolutions can be combined, each measuring independent and distinct geophysical parameters, to quantify the competing physical processes, i.e., isostatic uplift, interseismic vertical deformation, permafrost degradation, crustal uplift resulting from elastic loading effect from mountain glacier ablation, and possible glacial isostatic ad- justment effect. The surface motions can be measured by satellite altimetry over the solid Earth and by GPS/leveling, while the combined surface and subsurface signals in theory can be measured by GRACE, at a resolution of several hundred $\mathrm{km}$.

Our study shows that all of the mentioned processes have comparable effects to the satellite geodetic signals. However, their spatial coverage are different; e.g., permafrost degradation may be dominant in the western region whereas isostatic crustal uplift may dominate in the northeast and southeast. Vertical motions due to interseismic 
deformation are only significant within $10-15 \mathrm{~km}$ of the vicinity of the fault zones. It has been concluded that the expected GRACE signal due to isostatic crustal thickening is negligibly small, likely because of the cancelling effects of the Moho deepening and the surface uplift. However, the non-isostatic effects of crustal thickening near the margins and their possible sensitivity to a suite of modern geodetic sensors still need to be investigated.

Acknowledgements This research is partially supported by grants from Ohio State University's Climate, Water, and Carbon Program (http://cwc.osu.edu), and from NASA. Hansheng Wang is supported by National Natural Science Foundation of China (40825012). We thank the anonymous reviewers and the Editor, Cheinway Hwang, for their constructive comments. The TOPEX/POSEIDON Geophysical and Sensor Data Records are from NASA and CNES, and the GRACE data products are from University of Texas Center for Space Research via NASA JPL's PODAAC. JinWoo Kim helped creating the schematic figure illustrating competing geophysical processes over the Tibetan Plateau. We thank Rongjiang Wang, GeoForschungsZentrum Potsdam (GFZ), for kindly providing us his dislocation code used in this study. We thank Qi Wang for providing the updated GPS velocity figure.

\section{REFERENCES}

An, M. and Y. Shi, 2007: Three-dimensional thermal structure of the Chinese continental crust and upper mantle. Sci. China Ser. D: Earth Sci., 50, 1441-1451, doi: 10.1007/s11430-007-0071-3. [Link]

Beaumont, C., R. A. Jamieson, M. H. Nguyen, and S. Medvedev, 2004: Crustal channel flows: 1 . Numerical models with applications to the tectonics of the HimalayanTibetan orogen. J. Geophys. Res., 109, B06406, doi: 10.1029/2003JB002809. [Link]

Bird, P., 1991: Lateral extrusion of lower crust from under high topography in the isostatic limit. J. Geophys. Res., 96, 10275-10286, doi: 10.1029/91JB00370. [Link]

Braitenberg, C., M. Zadro, J. Fang, Y. Wang, and H. T. Hsu, 2000: The gravity and isostatic Moho undulations in Qinghai-Tibet plateau. J. Geodyn., 30, 489-505, doi: 10.1016/S0264-3707(00)00004-1. [Link]

Cogley, J. G., 2009: Geodetic and direct mass-balance measurements: Comparison and joint analysis. Ann. Glaciol., 50, 96-100, doi: 10.3189/172756409787769744. [Link]

Derbyshire, E., Y. Shi, J. Li, B. Zheng, S. Li, and J. Wang, 1991: Quaternary glaciation of Tibet: The geological evidence. Quat. Sci. Rev., 10, 485-510, doi: 10.1016/0277-3791(91)90042-S. [Link]

Duan, X. J., J. Y. Guo, C. K. Shum, and W. van der Wal, 2009: On the postprocessing removal of correlated er- rors in GRACE temporal gravity field solutions. J. Geodesy, 83, 1095-1106, doi: 10.1007/s00190-009-03270, doi: 10.1007/s00190-009-0327-0. [Link]

Dyurgerov, M. B. and M. Meier, 2005: Glaciers and changing Earth system. A 2004 snapshot, Institute of Arctic and Alpine Research, University of Colorado, Boulder.

England, P. and G. Houseman, 1986: Finite strain calculations of continental deformation 2. Comparison with the India-Asia collision zone. J. Geophys. Res., 91, 3664-3676, doi: 10.1029/JB091iB03p03664. [Link]

Guo, J. Y., X. J. Duan, and C. K. Shum, 2010: Non-isotropic Gaussian smoothing and leakage reduction for determining mass changes over land and ocean using GRACE data. Geophys. J. Int., 181, 290-302, doi: 10.1111/j.1365-246X.2010.04534.x. [Link]

Jackson, M. and R. Bilham, 1994: Constraints on Himalayan deformation inferred from vertical velocity fields in Nepal and Tibet. J. Geophys. Res., 99, 13897-13912, doi: 10.1029/94JB00714. [Link]

Jiménez-Munt, I., M. Fernàndez, J. Vergés, and J. P. Platt, 2008: Lithosphere structure underneath the Tibetan Plateau inferred from elevation, gravity and geoid anomalies. Earth Planet. Sci. Lett., 267, 276-289, doi: 10.1016/j.epsl.2007.11.045. [Link]

Jin, Y., M. K. McNutt, and Y. Zhu, 1994: Evidence from gravity and topography data for folding of Tibet. $\mathrm{Na}$ ture, 371, 669-674, doi: 10.1038/371669a0. [Link]

Kaser, G., J. G. Cogley, M. B. Dyurgerov, M. F. Meier, and A. Ohmura, 2006: Mass balance of glaciers and ice caps: Consensus estimates for 1961-2004. Geophys. Res. Lett., 33, L19501, doi: 10.1029/2006GL027511. [Link]

Kaufmann, G., 2005: Geodetic signatures of a late Pleistocene Tibetan ice sheet. J. Geodyn., 39, 111-125, doi: 10.1016/j.jog.2004.08.005. [Link]

Kuhle, M., 1988: The Pleistocene glaciation of Tibet and the onset of ice ages - An autocycle hypothesis. GeoJournal, 17, 581-595, doi: 10.1007/BF00209444. [Link]

Lee, H., C. K. Shum, C. Y. Kuo, Y. Yi, and A. Braun, 2008a: Application of TOPEX altimetry for solid Earth deformation studies. Terr. Atmos. Ocean. Sci., 19, 37-46, doi: 10.3319/TAO.2008.19.1-2.37(SA). [Link]

Lee, H., C. K. Shum, Y. Yi, A. Braun, and C. Y. Kuo, 2008b: Laurentia crustal motion observed using TOPEX/POSEIDON radar altimetry over land. J. Geodyn., 46, 182-193, doi: 10.1016/j.jog.2008.05.001. [Link]

Lee, H., C. K. Shum, K. H. Tseng, J. Y. Guo, and C. Y. Kuo, 2011: Present-day lake level variation from Envisat altimetry over the northeastern Qinghai-Tibetan Plateau: Links with precipitation and temperature. Terr. Atmos. Ocean. Sci., 22, 169-175, doi: 10.3319/ TAO.2010.08.09.01(TibXS) [Link]

Li, S., W. D. Mooney, and J. Fan, 2006: Crustal structure of mainland China from deep seismic sounding data. Tec- 
tonophysics, 420, 239-252, doi: 10.1016/j.tecto.2006. 01.026. [Link]

Matsuo, K. and K. Heki, 2010: Time-variable ice loss in Asian high mountains from satellite gravimetry. Earth Planet. Sci. Lett., 290, 30-36, doi: 10.1016/j.epsl.2009. 11.053. [Link]

Meade, B. J., 2007: Present-day kinematics at the India-Asia zone. Geology, 35, 81-84, doi: 10.1130/G22924A.1. [Link]

Molnar, P., P. England, and J. Martinod, 1993: Mantle dynamics, uplift of the Tibetan Plateau, and the Indian Monsoon. Rev. Geophys., 31, 357-396, doi: 10.1029/ 93RG02030. [Link]

Mulch, A. and C. P. Chamberlain, 2006: Earth science: The rise and growth of Tibet. Nature, 439, 670-671, doi: 10.1038/439670a. [Link]

Oelke, C. and T. Zhang, 2007: Modeling the active-layer depth over the Tibetan Plateau. Arctic, Antarctic, and Alpine Res., 39, 714-722, doi: 10.1657/1523-0430(06200)[OELKE]2.0.CO;2. [Link]

Ohmura, A., 2009: Completing the world glacier inventory. Ann. Glaciol., 50, 144-148.

Paulson, A., S. Zhong, and J. Wahr, 2007: Limitations on the inversion for mantle viscosity from postglacial rebound. Geophys. J. Int., 168, 1195-1209, doi: 10.1111/j.1365-246X.2006.03222.x. [Link]

Pavlis, N. K., S. A. Holmes, S. C. Kenyon, and J. K. Factor, 2008: An earth gravitational model to degree 2160: EGM2008. Presented at the 2008 General Assembly of the European Geosciences Union, Vienna, Austria, April 13-18.

Qiu, J., 2008: China: The third pole. Nature, 454, 393-396, doi: 10.1038/454393a. [Link]

Rodell, M., I. Velicogna, and J. S. Famiglietti, 2009: Satellite-based estimates of groundwater depletion in India. Nature, 460, 999-1002, doi: 10.1038/nature08238. [Link]

Rowley, D. B. and B. S. Currie, 2006: Palaeo-altimetry of the late Eocene to Miocene Lunpola basin, central Tibet. Nature, 439, 677-681, doi: 10.1038/nature04506. [Link]

Royden, L. H., B. C. Burchfiel, R. W. King, E. Wang, Z. Chen, F. Shen, and Y. Liu, 1997: Surface deformation and lower crustal flow in eastern Tibet. Science, 276, 788-790, doi: 10.1126/science.276.5313.788. [Link]

Shin, Y. H., C. K. Shum, C. Braitenberg, S. M. Lee, H. Xu, K. S. Choi, J. H. Baek, and J. U. Park, 2009: Threedimensional fold structure of the Tibetan Moho from GRACE gravity data. Geophys. Res. Lett., 36, L01302, doi: 10.1029/2008GL036068. [Link]

Sun, W., Q. Wang, H. Li, Y. Wang, S. Okubo, D. Shao, D. Liu, and G. Fu, 2009: Gravity and GPS measurements reveal mass loss beneath the Tibetan Plateau: Geodetic evidence of increasing crustal thickness. Geophys.
Res. Lett., 36, L02303, doi: 10.1029/2008GL036512. [Link]

Swenson, S. and J. Wahr, 2002: Methods for inferring regional surface-mass anomalies from Gravity Recovery and Climate Experiment (GRACE) measurements of time-variable gravity. J. Geophys. Res., 107, 2193, doi: 10.1029/2001JB000576. [Link]

Swenson, S. and J. Wahr, 2006: Post-processing removal of correlated errors in GRACE data. Geophys. Res. Lett., 33, L08402, doi: 10.1029/2005GL025285. [Link]

Tapley, B. D., S. Bettadpur, J. C. Ries, P. F. Thompson, and M. M. Watkins, 2004: GRACE measurements of mass variability in the Earth system. Science, 305, 503-505, doi: 10.1126/science.1099192. [Link]

Tapponnier, P., Z. Xu, F. Roger, B. Meyer, N. Arnaud, G. Wittlinger, and J. Yang, 2001: Oblique stepwise rise and growth of the Tibet Plateau. Science, 294, 16711677, doi: 10.1126/science.105978. [Link]

Tiwari, V. M., J. Wahr, and S. Swenson, 2009: Dwingling groundwater resources in northern India, from satellite gravity observations. Geophys. Res. Lett., 36, L18401, doi: 10.1029/2009GL039401. [Link]

Wang, B. and H. M. French, 1995: Permafrost on the Tibet Plateau, China. Quat. Sci. Rev., 14, 255-274, doi: 10.1016/0277-3791(95)00006-B. [Link]

Wang, H., 2001: Effects of glacial isostatic adjustment since the late Pleistocene on the uplift of the Tibetan Plateau. Geophys. J. Int., 144, 448-458, doi: 10.1046/j.1365-24 6x.2001.00340.x. [Link]

Wang, Q., P. Z. Zhang, J. T. Freymueller, R. Bilham, K. M. Larson, X. Lai, X. You, Z. Niu, J. Wu, Y. Li, J. Liu, Z. Yang, and Q. Chen 2001: Present-day crustal deformation in China constrained by Global Positioning System measurements. Science, 294, 574-577, doi: 10.1126/science.1063647. [Link]

Wang, Q., D. Cui, W. Wang, S. Zhang, J. Liu, and Q. Shi, 2008: Present-day vertical crustal motion of Sichuan from leveling. Chin. Sci. D: Earth Study, Sci. China Press, 38, 598-610.

Wang, R., F. Lorenzo-Martín, and F. Roth, 2006: PSGRN/ PSCMP - A new code calculating co- and post-seismic deformation, geoid, and gravity changes based on the viscoelastic-gravitational dislocation theory. Comput. Geosci., 32, 527-541, doi: 10.1016/j.cageo.2005.08.0 06. [Link]

Wang, S., H. Jin, S. Li, and L. Zhao, 2000: Permafrost degradation on the Qinghai-Tibet Plateau and its environmental impacts. Permafrost Periglacial Process., 11, 43-53, doi: 10.1002/(SICI)1099-1530(200001/03) 11:1<43::AID-PPP332>3.0.CO;2-H. [Link]

Xiong, X., R. Gao, Q. Li, and Z. Lu, 2009: Moho depth of Qinghai-Tibet plateau revealed by seismic probing. J. Earth Sci., 20, 448-463, doi: 10.1007/s12583-0090037-9. [Link] 
Xu, C., J. Liu, C. Song, W. Jiang, and C. Shi, 2000: GPS measurements of present-day uplift in the southern Tibet. Earth Planets Space, 52, 735-739.

Xu, X., C. Lu, X. Shi, and S. Gao, 2008: World water tower: An atmospheric perspective. Geophys. Res. Letts., 35, L20815, doi: 10.1029/2008GL035867. [Link]

Yao, Y. B., 2008: Analysis of crustal movement characteristics in the China mainland by high precision repeated measurements of GPS network. Progress in Geophysics, 23, 1030-1037.

Zhang, T., R. G. Barry, K. Knowles, J. A. Heginbottom, and J. Brown, 2008: Statistics and characteristics of permafrost and ground-ice distribution in the
Northern Hemisphere. Polar Geogr., 31, 47-68, doi: 10.1080/10889370802175895. [Link]

Zhang, Z., S. Geng, D. Chen, S. Ying, Z. Wang, Z. He, S. Xia, and J. Wang, 1989: Rate of recent vertical crustal deformation. In: Ma, X., G. Ding, W. Gao, H. Zhang, B. Zhang, and Z. Ma, (Eds.), Lithospheric Dynamics Atlas of China, China Cartographic Publishing House, Beijing, China, 18.

Zhao, L., G. Chen, G. Cheng, and S. Li, 2000: Permafrost: Status, variation, and impacts. In: Zheng, D., Q. Zheng, and S. Wu (Eds.), Mountain Geoecology and Sustainable Development of the Tibetan Plateau, Kluwer Academic Publishers, 113-117. 